\title{
Time spent on work-related activities, social activities and time pressure as intermediary determinants of health disparities among elderly women and men in 5 European countries: a structural equation model
}

Nicholas Kofi Adjei ${ }^{1,2,4^{*}}$, Kenisha Russell Jonsson ${ }^{3}$ and Tilman Brand ${ }^{1}$

\begin{abstract}
Background: Psychosocial factors shape the health of older adults through complex inter-relating pathways. Besides socioeconomic factors, time use activities may explain gender inequality in self-reported health. This study investigated the role of work-related and social time use activities as determinants of health in old age. Specifically, we analysed whether the impact of stress in terms of time pressure on health mediated the relationship between work-related time use activities (i.e. housework and paid work) on self-reported health.

Methods: We applied structural equation models and a maximum-likelihood function to estimate the direct and indirect effects of psychosocial factors on health using pooled data from the Multinational Time Use Study on 11,168 men and 14,295 women aged 65+ from Italy, Spain, UK, France and the Netherlands.

Results: The fit indices for the conceptual model indicated an acceptable fit for both men and women. The results showed that socioeconomic status (SES), demographic factors, stress and work-related time use activities after retirement had a significant direct influence on self-reported health among the elderly, but the magnitude of the effects varied by gender. Social activities had a positive impact on self-reported health but had no significant impact on stress among older men and women. The indirect standardized effects of work-related activities on selfreported health was statistically significant for housework ( $\beta=-0.006 ; P<0.001$ among men and $\beta=-0.008 ; P<0$. 001 among women) and paid work ( $\beta=0.012 ; P<0.01$ among men and $\beta=0.000 ; P>0.05$ among women), which implied that the paths from paid work and housework on self-reported health via stress (mediator) was very weak because their indirect effects were close to zero.

Conclusions: Our findings suggest that although stress in terms of time pressure has a direct negative effect on health, it does not indirectly influence the positive effects of work-related time use activities on self-reported health among elderly men and women. The results support the time availability hypothesis that the elderly may not have the same time pressure as younger adults after retirement.
\end{abstract}

Keywords: Psychosocial factors, Self-reported health, Gender, Elderly, Time-use activities, Stress

\footnotetext{
*Correspondence: adjei@uni-bremen.de; nicholasadjei@gmail.com

${ }^{1}$ Department of Prevention and Evaluation, Leibniz Institute for Prevention

Research and Epidemiology - BIPS, Unit Social Epidemiology, Achterstrasse

30, D-28359 Bremen, Germany

${ }^{2}$ Health Sciences Bremen, University of Bremen, Bremen, Germany

Full list of author information is available at the end of the article
}

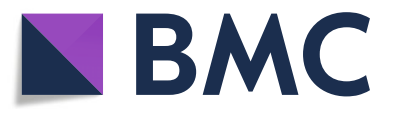

(c) The Author(s). 2018 Open Access This article is distributed under the terms of the Creative Commons Attribution 4.0 International License (http://creativecommons.org/licenses/by/4.0/), which permits unrestricted use, distribution, and reproduction in any medium, provided you give appropriate credit to the original author(s) and the source, provide a link to the Creative Commons license, and indicate if changes were made. The Creative Commons Public Domain Dedication waiver (http://creativecommons.org/publicdomain/zero/1.0/) applies to the data made available in this article, unless otherwise stated. 


\section{Background}

Gender differences in health among the elderly have been reported in several studies [1-4]. Similar findings among younger adults $[5,6]$, affirms the long-standing health-survival paradox that women live longer than men, yet they report poorer health $[7,8]$. However, there is some evidence that suggests non-existence of gender differences in self-reported health among the elderly in some high-income countries such as the UK, the US and Finland $[9,10]$. Thus, the paradox may be country-specific as previously shown for some welfare countries [11]. Furthermore, health differences may be dependent on the health outcomes and phase of the life cycle [9]. The reasons for these observed gender disparities in health are complex and interrelated, but the most cited explanations are differences in biological traits [12-14]. Nonetheless, epidemiological research suggests that biological factors are not sufficient in explaining the health gap between women and men [12, 15].

From a health inequality perspective, several explanatory factors have been suggested [3, 15-17], most of which have been linked to differences in socioeconomic positions such as education, income, and occupation as the main sources of inequality between men and women. Studies have shown that socioeconomic position is often lower among women and thus they are exposed to high levels of stress [18], and among the elderly, they are exposed to a wide range of psychosocial risk factors, when in a lower socioeconomic position [19]. Furthermore, the differential vulnerability hypothesis also suggests that there may be variations by gender in vulnerability to behavioral and psychological health conditions [2].

Notwithstanding the importance of biological and socioeconomic forces in explaining the health disparities between men and women, these factors may not be sufficient for understanding the health gap seen between elderly persons of different gender. A further explanation may be linked to results from post-retirement time use studies which revealed that older men and women often are engaged in social roles and activities such as housework activities [20,21], leisure activities [20,22] and voluntary work [23-25] to different degree.

In this regard, social roles and the time invested in such activities, summarized here as time use activities, may to some extent explain the gender differences in health [26]. Studies that used the concept of social roles such as marital status (i.e., being married, divorced, separated or widowed), to examine these relationships concluded that social roles that people occupy may have an impact on their health [27, 28]. However, Bird and Fremont [26] have pointed out that these indicators of social roles are crude and indirect and thus time and effort spent on social roles and activities should be investigated.

Among the elderly, time use activities may be an important determinant of health considering the time availability after retirement [20, 29]. Interestingly, evidence suggests that gender inequality in work-related time use activities (i.e., paid work and housework) persist in high-income countries even after retirement [11, 30]. While elderly men allocate more time to paid work, older women allocate more time to housework activities $[29,31,32]$, even though time allocated to housework activities among older men has increased over the years [31]. Regarding these household activities, men typically perform the occasional tasks while women are responsible for routine housework [33, 34]. Despite the gender differences in the distribution of housework, performing these activities are deemed "productive activities" [35] because they are activities that older adults might have delegated to a paid worker.

The inequitable distribution of work-related time use activities may be a contributing factor for the observed gender health differences [36, 37]. Although moderate time spent on these activities can be beneficial to health among the elderly [11], Luoh and Herzog [38] suggested that longer hours devoted to paid work activities might not necessarily improve the health among the elderly. In a recent study Adjei and Brand [39] concluded that older women have higher odds of reporting poor health when more time is devoted housework combined with either short or long sleep duration. The combination of more hours of housework and paid work activities has also been shown to be more stressful among women [40]. Moreover, longer time allocated to these activities may increase time pressures [41]. It may also reduce time availability for social activities such as participation in clubs and religious involvement [42], which may have positive health effects.

From the above discussions, it is clear that the literature on socioeconomic status, work-related activities and stress have identified a direct relationship with health among older adults. However, we argue that these psychosocial factors may have an indirect differential impact on health among men and women. Furthermore, stress in terms of time pressure can mediate the associations between health status and work-related activities, but we speculated in our previous papers [11, 39] that the strength of the relationship between these activities and self-reported health via stress might be weak, due to time availability at old age. However, this assertion has not yet been supported with empirical data among elderly men and women [11]. Our study therefore seeks to disentangle the mechanisms and pathways through which work-related activities, socioeconomic status and stress impact on the health status of the elderly. More specifically, we aimed to examine whether stress defined in terms of time pressure plays a mediating role in the relationship between work-related activities and self-reported health. 


\section{Methods}

\section{Data}

Data from the Multinational Time Use Study (MTUS, version W53) were used for this study. MTUS is a cross-national harmonized and comparative time-use database from 25 countries, collated and organized by the Centre for Time Use Research at the University of Oxford [43]. Diaries were self-administered followed by a personal visit in most countries. In the interview, diarist reported the total time spent on 41 activities over a 24-h period in 5,10 or 15 -min intervals during a randomly assigned day in a week in France, Italy and Spain, and two days (weekday and weekend) in the UK. In the Netherlands, diarist reported their time use activities for seven consecutive days [43]. For the purpose of this study, we limited our sample to participants who were 65 years and above and their time use activities sum up to $1440 \mathrm{~min}(24 \mathrm{~h})$. The countries considered in the final analysis were the United Kingdom (survey year: 2000; $n$ $=2870$ ), Spain (survey year: 2002; $n=9889$ ), Italy (survey year: 2002; $n=8709$ ), France (survey year: 1998; $n=$ 2231) and the Netherlands (survey year: 2000; $n=1764$ ). These countries were selected based on the availability of the health variable in the respective diary collection.

\section{Measures and model specification}

Structural equation models were used to test the proposed relationships between the concepts described in Fig. 1. This model reflected the hypothesized pathways between self-reported health and the psychosocial measures being assessed. Socioeconomic status (SES) was a latent variable, which was represented by a circle. This variable was measured by three observed indicators: education (less than secondary education, completed secondary education and above secondary education), wealth (measured by car ownership, and coded to indicate no car, one car and two or more cars) and employment status (not working for pay, currently in paid employment). Among older adults, these measures of SES have been shown to be associated with health $[4,44]$.

Self-reported health and stress in terms of time pressure, represented by rectangles, were the two key observed endogenous (dependent variables) used for this study. Self-reported health was assessed using the question: "How is your health in general; would you say that it is ...?" response options: zero (poor) to three (very good). We used the responses as a 4-level ordinal variable, where higher levels indicate better health. Intense time pressure, an indicator of stress [41], was measured using the following question: "Would you say you always feel rushed even to do the things you have to do, only sometimes feel rushed, or almost never feel rushed?" The responses were coded as: (1) never (2) sometimes and (3) always. It was used as an ordinal variable, with higher levels corresponding to stress.

In the model, we considered two work-related time use activities (housework and paid work), measured in hours per day, as these activities are associated with stress, depression and physical health status [26, 36, 45].

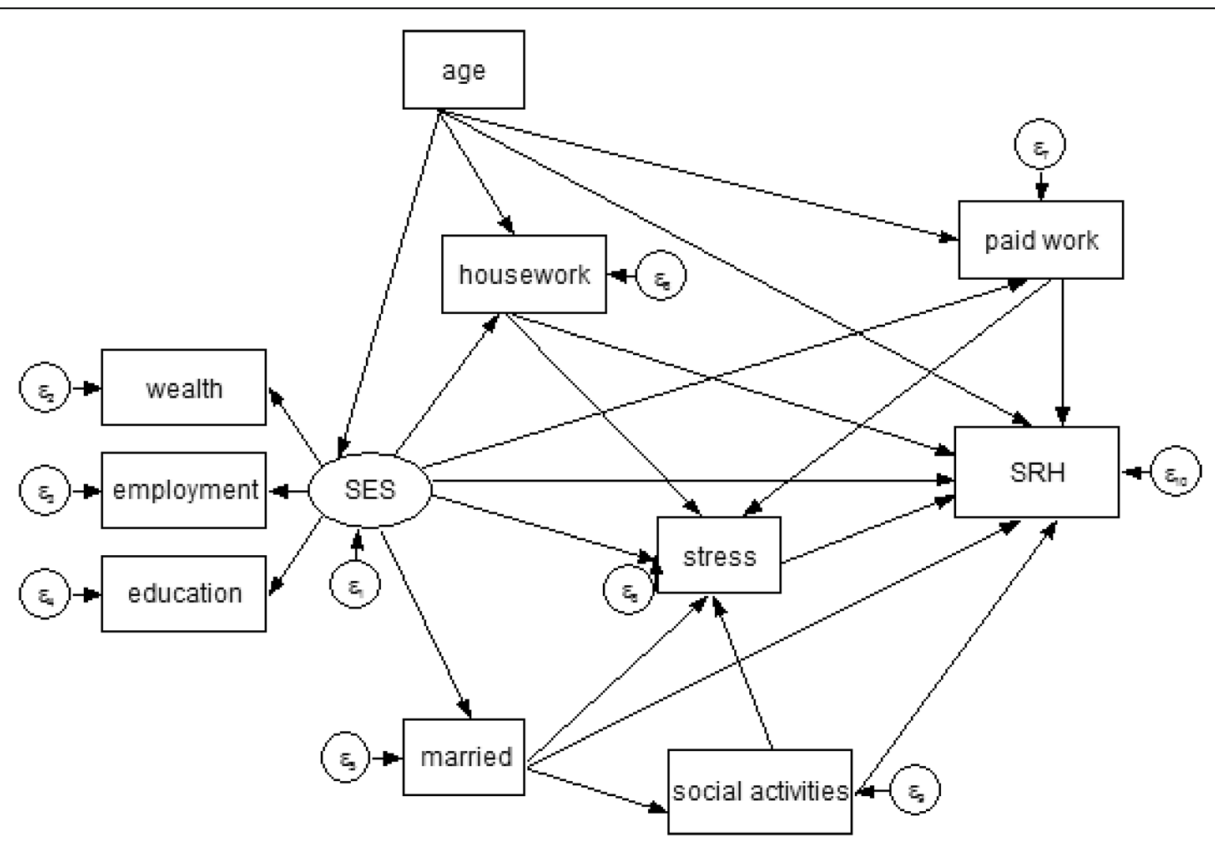

Fig. 1 Conceptual model of self-reported Health (SRH), stress measured by time pressure, socioeconomic status (SES), demographic factors, social activities and work-related time use activities (housework and paid work) among the elderly 
We also included marital status (married/cohabiting vs single/widowed) and age which previous studies have found to be associated with stress and general health status [46]. To investigate work-related time use activities and potential "stress buffers", we used time devoted to social activities [41], (measured in hours per day) (Fig. 1). Additional file 1: Table S2 lists the detailed time use activities included in the 3 broad categories used for this study.

\section{Analytic strategy}

The analytic strategy included four separate steps. First, descriptive analysis summarized gender differences in self-reported health, stress and other social factors including the mean time allocated to time use activities. Second, Pearson's correlations coefficients $(r)$ were estimated to examine the bivariate correlations of all measured variables. Third, a linear structural model was implemented and estimated using a maximum-likehood function [47]. This was aimed at estimating the direct and indirect relationship between self-reported health, stress, time use activities and other social factors. This can be expressed mathematically as follows:

$$
\mathrm{Y}=\mathrm{BY}+\Gamma X+\alpha+\varsigma
$$

where, = vector of the endogenous variables (self-reported health and stress); $X=$ vector of the exogenous variables, both latent (SES) and observed (age, marital status, paidwork, housework and social activities); B and $\Gamma=$ matrices of the coefficients; $\alpha=$ vector of the intercepts; $\varsigma=$ vector of the error terms.

Finally, a model for the indirect and total effects of housework and paidwork via stress was constructed. The assumption was that stress in terms of time pressure did not mediate the relationship between these work-related time use activities and self-reported health, due to time availability at old age [11]. We use the term "effect" in its technical sense and do not want to imply causation [48].

In order to test the hypothesis, we used stress as a mediating variable to estimate the indirect and total effects of these activities on self-reported health. The total effect was obtained through the summation of the direct and indirect effects using Stata's estat teffects command, which can be expressed mathematically as follows:

$$
\mathrm{c}=\mathrm{c}^{\prime}+\mathrm{ab}
$$

Where, $\mathrm{c}=$ Total effect, $\quad \mathrm{c}^{\prime}=$ Direct effect,$\quad \mathrm{ab}=$ Indirect effect.

The chi-square $(x 2)$ is the traditional measure for assessing the overall goodness of fit of an SEM model [49], however, because it is highly sensitive to large samples [49], we considered the Comparative Fit Index (CFI), and the Root Mean Square Error of Approximation (RMSEA) suggested by Hooper et al. [49] to evaluate model fit. An RMSEA less than 0.06 shows a good fit. The CFI, on the other hand, ranges between 0 and 1 , where values closer to 1 indicate better model fit. A good fit was defined as values greater than 0.95 and values greater than 0.90 indicates an acceptable fit to the data [49]. The estat mindices command was used for the modification of the initial model and the final conceptual model was subsequently determined based on the chi-square $\left(x^{2}\right)$ test of additional paths from a theoretical view point. The analyses were done separately for men and women. All statistical analyses were performed in STATA version 14 [50].

\section{Results \\ Descriptive statistics}

Table 1 provides the distribution information of respondents, stratified by gender and Additional file 1: Tables S3 and S4 by country and gender. We observed that more elderly women than elderly men reported poorer health $(20.5 \%$ vs $15.1 \%)$. Women were more likely to report stress than men. Approximately $70.7 \%$ of elderly men reported never having any intense time pressure as compared to $58.3 \%$ of women. Gender differences were also found in socioeconomic factors. Women were on average older than men (73.1 years vs 72.4 years). However, more men than women were married or cohabiting (79.9\% vs $47.1 \%)$ and they also had higher educational attainment as compared to women. About $11 \%$ of elderly men and $5 \%$ of women reported having a tertiary education (Table 1).

Work-related time use activities (housework and paid work) varied considerably among elderly men and women. Women spent more time on housework activities $(4.85 \mathrm{~h} /$ day vs $2.82 \mathrm{~h} /$ day), while men spent more time in paid work $(0.26 \mathrm{~h} /$ day vs $0.08 \mathrm{~h} /$ day). However, a cross-country comparison in Additional file 1: Table S1 shows that the most time devoted to housework activities was found among women in Italy $(5.15 \mathrm{~h} /$ day), while the least was observed in the Netherlands (4.44 h/ day). Elderly women spent remarkably fewer hours in paid work compared to men. We observed that there were no differences in time devoted to paid work among women in Italy, Spain and France. The lowest value was observed in these countries $(0.07 \mathrm{~h} /$ day $)$, while most time spent in paid work was found in the Netherlands (0.11 h per day).

Regarding time allocation to social activities, men devoted on average $1.21 \mathrm{~h} /$ day to these activities as compared to $1.10 \mathrm{~h} /$ day for women. The highest value was found in the Netherlands for men and women $(1.73 \mathrm{~h} /$ 
Table 1 General description of the study sample (in percentages, means, 95\% Cl and SD), men and women

\begin{tabular}{|c|c|c|c|c|c|c|}
\hline & \multicolumn{3}{|c|}{$\begin{array}{l}\text { Men } \\
(n=11,168)\end{array}$} & \multicolumn{3}{|c|}{$\begin{array}{l}\text { Women } \\
(n=14,295)\end{array}$} \\
\hline & Mean/\% & SD & $(95 \% \mathrm{Cl})$ & Mean/ \% & SD & $(95 \% \mathrm{Cl})$ \\
\hline \multicolumn{7}{|l|}{ Self-reported health } \\
\hline Poor & 15.1 & & $(14.4-15.8)$ & 20.5 & & $(19.9-21.1)$ \\
\hline Fair & 44.5 & & $(43.6-45.4)$ & 47.0 & & $(46.1-47.8)$ \\
\hline Good & 32.5 & & $(31.7-33.4)$ & 26.1 & & $(25.4-26.9)$ \\
\hline Very good & 7.9 & & $(7.4-8.4)$ & 6.4 & & $(5.9-6.8)$ \\
\hline \multicolumn{7}{|l|}{ Stress } \\
\hline Almost never & 70.7 & & $(69.8-71.5)$ & 58.3 & & $(57.5-59.1)$ \\
\hline Sometimes & 23.3 & & $(22.5-24.1)$ & 31.7 & & $(30.9-32.4)$ \\
\hline Often & 6.0 & & $(5.5-6.4)$ & 10.0 & & $(9.4-10.4)$ \\
\hline \multicolumn{7}{|l|}{ Sociodemographic \& economic factors } \\
\hline Age & 72.40 & 5.01 & & 73.06 & 5.13 & \\
\hline $65-69$ & 35.3 & & $(34.3-36.1)$ & 31.0 & & $(30.2-31.7)$ \\
\hline $70-74$ & 29.0 & & $(28.1-29.7)$ & 27.7 & & $(26.9-28.4)$ \\
\hline $75-79$ & 20.2 & & $(19.4-20.9)$ & 20.8 & & $(20.1-21.5)$ \\
\hline $80+$ & 15.6 & & $(14.9-16.3)$ & 20.5 & & $(19.8-21.1)$ \\
\hline \multicolumn{7}{|l|}{ Marital Status } \\
\hline Single/widowed & 20.2 & & $(19.4-20.9)$ & 52.9 & & $(52.1-53.7)$ \\
\hline Married/Cohabiting & 79.9 & & $(79.0-80.5)$ & 47.1 & & $(46.2-47.8)$ \\
\hline \multicolumn{7}{|l|}{ Education } \\
\hline Incomplete Sec. or less & 60.9 & & $(60.0-61.8)$ & 73.3 & & $(72.6-74.0)$ \\
\hline Secondary completed & 28.0 & & $(27.1-28.8)$ & 21.4 & & $(20.7-22.1)$ \\
\hline Tertiary Completed or above & 11.1 & & $(10.4-11.6)$ & 5.2 & & $(4.8-5.6)$ \\
\hline \multicolumn{7}{|l|}{ Wealth } \\
\hline Car ownership & 2.46 & 1.45 & & 1.84 & 1.61 & \\
\hline No car & 24.1 & & $(23.3-24.9)$ & 41.6 & & $(40.7-42.4)$ \\
\hline 1 car & 52.5 & & $(51.5-53.4)$ & 39.4 & & $(38.6-40.2)$ \\
\hline $2+$ cars & 23.4 & & $(22.5-24.1)$ & 19.0 & & $(18.3-19.6)$ \\
\hline \multicolumn{7}{|l|}{ Employment Status } \\
\hline Not working for pay & 94.9 & & $(94.4-95.2)$ & 98.1 & & $(97.8-98.2)$ \\
\hline Currently in paid employment & 5.1 & & $(4.7-5.5)$ & 1.9 & & $(1.7-2.1)$ \\
\hline \multicolumn{7}{|l|}{ Time use Activities } \\
\hline Paid work hours/day & 0.26 & 1.36 & & 0.08 & 0.71 & \\
\hline $\mathrm{Oh}$ & 94.9 & & $(94.5-95.3)$ & 98.1 & & $(97.8-98.3)$ \\
\hline$>0 \mathrm{~h}$ & 5.1 & & $(4.6-5.4)$ & 1.9 & & $(1.6-2.1)$ \\
\hline House work hours/day & 2.82 & 2.51 & & 4.85 & 2.63 & \\
\hline Less than $1 \mathrm{~h}$ & 29.2 & & $(28.3-30.0)$ & 9.0 & & $(8.5-9.4)$ \\
\hline 1 to $3 \mathrm{~h}$ & 27.9 & & $(27.0-28.7)$ & 14.4 & & $(13.8-14.9)$ \\
\hline 3 to $6 \mathrm{~h}$ & 31.4 & & $(30.4-32.2)$ & 44.5 & & $43.7-45.3)$ \\
\hline$>6 \mathrm{~h}$ & 11.6 & & $(10.9-12.1)$ & 32.1 & & $(31.2-32.8)$ \\
\hline Social activities hours/day & 1.21 & 1.83 & & 1.10 & 1.68 & \\
\hline Less than $2 \mathrm{~h}$ & 76.2 & & (75.4-77.0) & 79.0 & & $(78.2-79.6)$ \\
\hline 2 to $4 \mathrm{~h}$ & 16.6 & & $(15.9-17.2)$ & 15.2 & & (14.6-15.8) \\
\hline
\end{tabular}


Table 1 General description of the study sample (in percentages, means, 95\% Cl and SD), men and women (Continued)

\begin{tabular}{|c|c|c|c|c|c|c|}
\hline & \multicolumn{3}{|c|}{$\begin{array}{l}\text { Men } \\
(n=11,168)\end{array}$} & \multicolumn{3}{|c|}{$\begin{array}{l}\text { Women } \\
(n=14,295)\end{array}$} \\
\hline & Mean/ \% & SD & (95\% Cl) & Mean/ \% & SD & $(95 \% \mathrm{Cl})$ \\
\hline$>4 \mathrm{~h}$ & 7.2 & & $(6.7-7.6)$ & 5.8 & & $(5.4-6.2)$ \\
\hline
\end{tabular}

day vs $1.67 \mathrm{~h} /$ day), the least among men in Spain $(0.97 \mathrm{~h} /$ day $)$ and women in France $(0.88 \mathrm{~h} /$ day $)$.

\section{Bivariate analysis}

The results of the bivariate analysis (Pearson correlation) between all measured variables are shown in Tables 2 (separated by gender).

Overall, the correlational pattern was very similar among women and men. The bivariate analysis showed that stress was negatively associated with self-reported health among elderly men $(r=-0.16)$ and women $(r=-$ 0.17 ). All three measures of socioeconomic status including education, wealth and employment were positively associated with self-reported health among both genders. Educational attainment showed the strongest correlation among men $(r=0.20)$ and women $(r=0.21)$. Employment and wealth were positively associated with stress for both genders. Meanwhile, educational attainment was found to be negatively associated with stress among women $(r=-0.02)$, but not statistically significant for men. Age was significantly and negatively associated with self-reported and stress among elderly men and women. Housework and paid work were positively associated with self-reported health and stress. However, the correlation between stress and these time use activities were low. Surprisingly, social activities were not associated with stress for both genders.

\section{Estimates of direct, indirect and total associations}

Table 3 and Figs. 2 and 3 present the estimated direct, indirect and total effects on key outcomes from the structural equation models.

Overall, SES had the greatest direct positive effect on stress among men $(\beta=0.182)$. Among women,

Table 2 Correlations between all measured variables by gender

\begin{tabular}{|c|c|c|c|c|c|c|c|c|c|c|}
\hline & (1) & (2) & (3) & (4) & (5) & (6) & (7) & (8) & (9) & (10) \\
\hline \multicolumn{11}{|l|}{ Men } \\
\hline \multicolumn{11}{|l|}{ Self-reported health (1) } \\
\hline Stress (2) & $-0.162^{* * *}$ & & & & & & & & & \\
\hline Age (3) & $-0.165^{* * *}$ & $-0.019^{*}$ & & & & & & & & \\
\hline Married (4) & $0.035^{* * *}$ & $0.026^{* *}$ & $-0.153^{* * *}$ & & & & & & & \\
\hline Education (5) & $0.201^{* * *}$ & 0.007 & $-0.081^{* * *}$ & $0.043^{* * *}$ & & & & & & \\
\hline Employment status (6) & $0.096^{* * *}$ & $0.095^{* * *}$ & $-0.120^{* * *}$ & $0.031^{* * *}$ & $0.087^{* * *}$ & & & & & \\
\hline Wealth (7) & $0.135^{* * *}$ & $0.069^{* * *}$ & $-0.228^{* * *}$ & $0.120^{* * *}$ & $0.154^{* * *}$ & $0.138^{* * *}$ & & & & \\
\hline Housework (8) & $0.163^{* * *}$ & $0.022^{*}$ & $-0.129^{* * *}$ & $-0.052^{* * *}$ & $0.024^{* *}$ & $-0.089^{* * *}$ & $0.062^{* * *}$ & & & \\
\hline Paid work (9) & $0.082^{* * *}$ & $0.067^{* * *}$ & $-0.094^{* * *}$ & 0.017 & $0.081^{* * *}$ & $0.595^{* * *}$ & $0.114^{* * *}$ & $-0.125^{* * *}$ & & \\
\hline Social support (10) & $0.084^{* * *}$ & -0.004 & $-0.099^{* * *}$ & $-0.043^{* * *}$ & $0.062^{* * *}$ & 0.018 & $0.080^{* * *}$ & $-0.142^{* * *}$ & $-0.042^{* * *}$ & \\
\hline \multicolumn{11}{|l|}{ Women } \\
\hline \multicolumn{11}{|l|}{ Self-reported health (1) } \\
\hline Stress (2) & $-0.159^{* * *}$ & & & & & & & & & \\
\hline Age (3) & $-0.169^{* * *}$ & $-0.086^{* * *}$ & & & & & & & & \\
\hline Married (4) & $0.054^{* * *}$ & $0.057^{* * *}$ & $-0.347^{* * *}$ & & & & & & & \\
\hline Education (5) & $0.211^{* * *}$ & $-0.018^{*}$ & $-0.128^{* * *}$ & $0.058^{* * *}$ & & & & & & \\
\hline Employment status (6) & $0.091^{* * *}$ & $0.024^{* * *}$ & $-0.089^{* * *}$ & $0.024^{* *}$ & $0.085^{* * *}$ & & & & & \\
\hline Wealth (7) & $0.119^{* * *}$ & $0.054^{* * *}$ & $-0.187^{* * *}$ & $0.213^{* * *}$ & $0.125^{* * *}$ & $0.052^{* * *}$ & & & & \\
\hline Housework (8) & $0.165^{* * *}$ & $0.072^{* * *}$ & $-0.317^{* * *}$ & $0.240^{* * *}$ & 0.007 & $-0.036^{* * *}$ & $0.050^{* * *}$ & & & \\
\hline Paid work (9) & $0.061^{* * *}$ & $0.021^{* *}$ & $-0.075^{* * *}$ & $0.027^{*}$ & $0.089^{* * *}$ & $0.553^{* * *}$ & $0.053^{* * *}$ & $-0.037^{* * *}$ & & \\
\hline Social support (10) & $0.101^{* * *}$ & -0.006 & $-0.057^{* * *}$ & $-0.081^{* * *}$ & $0.045^{* * *}$ & -0.011 & 0.014 & $-0.159^{* * *}$ & $-0.029 * * *$ & \\
\hline
\end{tabular}

Notes: ${ }^{* * *} p<0.001 ;{ }^{* *} p<0.01 ;{ }^{*} p<0.05$ 
housework had the greatest positive effect on stress $(\beta=$ $0.049)$, followed by SES $(\beta=0.028)$. Meanwhile, paid work had a negative effect on stress among men $(\beta=-$ $0.069)$, but it was not statistically significant among women. Nonetheless, both paid work and housework had a positive effect on self-reported health among older men and women. Although stress had a negative direct influence on self-reported health among men and women, we found that the paths from paid work and housework on self-reported health via stress (mediator) were very weak because the indirect effects were close to zero among both genders (Figs. 2 and 3). Hence, there was almost no difference between the direct and total effects of these work-related time use activities on self-reported health among elderly men and women.

\section{Discussion}

The primary objective of the current study was to investigate the complexity of the relationships between work-related time use activities (housework and paid work), socioeconomic status, stress in terms of time pressure and self-reported health among older people in high-income countries with particular attention to gender differences in the effects. Our study not only analyzed the direct effects but also indirect and total effects, in order to disentangle the mechanisms and pathways through which these variables impact the health status of elderly men and women. The underlying premise of the study was that psychosocial factors influence the

Table 3 Standardized direct effects on key outcomes from the Structural Equation Model (SEM)

\begin{tabular}{lll}
\hline Path & Men & Women \\
\hline Direct effects on Stress & & \\
Age & $0.003(0.009)$ & $-0.060(0.009)^{* * *}$ \\
Married/Cohabitation & $0.021(0.010)^{* *}$ & $0.024(0.009)^{* *}$ \\
SES & $0.182(0.027)^{* * *}$ & $0.028(0.021)$ \\
Housework & $0.040(0.009)^{* * *}$ & $0.049(0.009)^{* * *}$ \\
Paid work & $-0.069(0.025)^{* *}$ & $-0.003(0.017)$ \\
Social activities & $-0.001(0.009)$ & $0.001(0.009)$
\end{tabular}

Direct effects on Self-reported health

$\begin{array}{lll}\text { Age } & -0.118(0.009)^{* * *} & -0.125(0.008)^{* * *} \\ \text { Married/Cohabitation } & 0.033(0.009)^{* * *} & -0.009(0.008) \\ \text { SES } & 0.237(0.036)^{* * *} & 0.328(0.054)^{* * *} \\ \text { Stress } & -0.176(0.009)^{* * *} & -0.181(0.007)^{* * *} \\ \text { Housework } & 0.182(0.009)^{* * *} & 0.162(0.008)^{* * *} \\ \text { Paid work } & 0.108(0.009)^{* * *} & 0.065(0.008)^{* * *} \\ \text { Social activities } & 0.103(0.009)^{* * *} & 0.119(0.008)^{* * *}\end{array}$

Notes: Significance level: ${ }^{* * *} p<0.001 ;{ }^{* *} p<0.01 ;{ }^{*} p<0.05$. Observed Information Matrix (OIM) standard errors in parentheses. Model fit: (CFI $=0.92$; RMSEA $=0.056$, with $90 \%$ C.I. $=0.054-0.059)$, and women (CFI $=0.89$; RMSEA $=$ 0.064 , with $90 \%$ C.I. $=0.062-0.068$ )

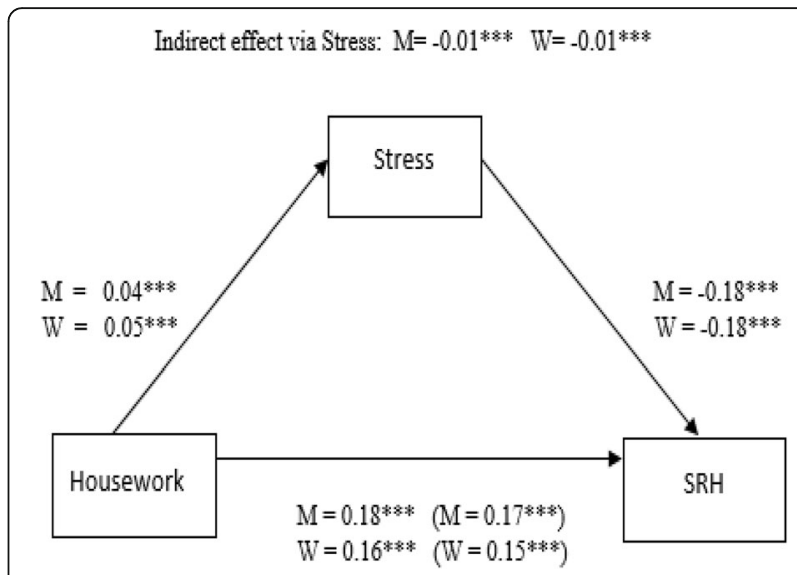

Fig. 2 Indirect effect of housework on self-reported health (SRH) via stress. Standardized coefficients, adjusted for socioeconomic status (SES), age, marital status, social activities and work-related time use activities. Coefficients for the total effects in parentheses. $M=$ men, $\mathrm{W}=$ women. ${ }^{* *} p<0.001 ;{ }^{* *} p<0.01 ;{ }^{*} p<0.05$

health status of older adults, however, these factors may also have an indirect differential impact among elderly men and women. Stress defined in terms of time pressure was thus viewed as a potential mediator in the relationships between social factors and health status (Fig. 1). Our study showed significant direct and indirect relationships between psychosocial factors and self-reported health among men and men, but there were gender differences in the magnitude of the associations. The key findings of the study can be summarized as follows. First, time devoted to housework and paid work was positively associated with self-reported health among elderly men and women. Second, whereas housework was positively associated with stress in both genders, paid work was negatively

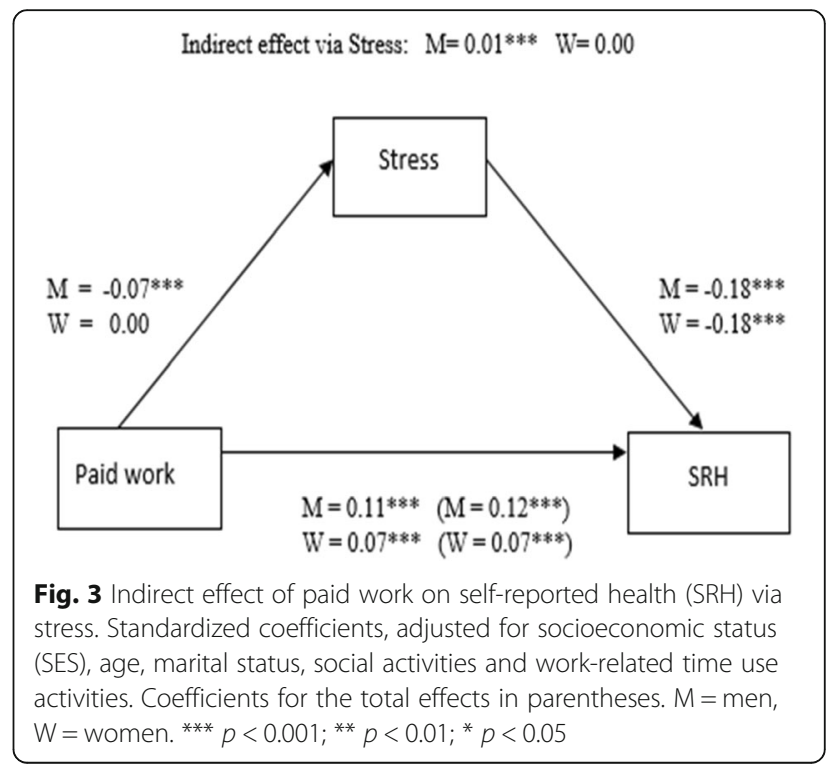


associated with stress only among men. Third, high levels of stress had a direct negative impact on self-reported health among elderly men and women, however, we confirmed that stress in terms of time pressure does not play a mediating role in the relationship between housework, paid work and self-reported health. Finally, social activities had a positive impact on self-reported health but had no significant impact on stress among older men and women.

\section{Relationship of the socioeconomic status, time use activities with the health outcomes by gender}

Prior evidence suggests that people with low SES are more likely to report poorer health compared to those with higher SES $[18,51,52]$. However, there may be variations in gender differences in vulnerability to socioeconomic status on health outcomes [53, 54], where women are more likely than men to report poorer physical health [11] and psychological distress [36]. In our study, we found that SES measured by education, wealth and employment was an independent predictor of health outcomes among elderly men and women. In line with previous studies $[55,56]$, we found a positive relationship between higher SES and good health status among the older population. A possible explanation for this outcome is that individuals with low SES may lack access to physical, psychological and environmental resources [52]. Also, it has been hypothesized that low SES leads to greater exposure to stress [18]. In contrast to this hypothesis, our direct effect models showed that stress in terms of time pressure is higher as SES increases among older men, but not statistically significant for women. The explanation to the diverging findings may be due to the measurement concept of stress [41], as this study only considered intense time pressure and not stressful life events such as financial strain [18]. Meanwhile, a recent study by Talala et al. [57] on SES and the distribution of stress found a reverse and curvilinear relationships.

The growing literature documenting partnership status and health among the elderly suggest that married $[58,59]$ and cohabiting older adults have better health than their unpartnered counterparts [60]. Although a variety of explanations have been given for these differences [61], social isolation and depression among single individuals are some of the psychological factors attributed to this physical health outcome [62]. However, data from several studies suggest that the protective effects of marriage on health are unequal among older men and women [63, 64] and that marriage appears to be more beneficial to men's health compared to women [64-66]. Results from the current study showed a positive relationship between marriage and self-reported health only among men. As previously noted [37], a possible explanation for this phenomenon may be gender differentials in stress exposure from marital responsibilities.
Nevertheless, the direct effects of relationship status in the present study indicated that both marriage/cohabitation was positively associated with stress as measured by time pressure among both men and women. This evidence and that of earlier studies [67] suggest that although marriage has an overall health benefit, it may not be a 'buffer' of stress even among the elderly. This is because the key sources of stress associated with marital roles [68] and poor marital quality among young and middle-aged adults [69] may be present among the older population.

Age was also significantly correlated with health in both elderly men and women, in line with the claim that the prevalence of good physical health decreases as age increases [11, 70]. However, age was negatively associated with stress among women but not statistically significant for men, a finding consistent with previous research that showed that older people experience less daily stress compared to midlife and younger adults $[71,72]$. This is mainly due to the differential roles of the elderly compared to younger adults. For instance, children are key sources of daily stress for working-age adults and older adults usually do not have the same parental roles and responsibilities with respect to child-rearing [71].

Time devoted to social activities was positively associated with health status for both older men and women, consistent with prior studies [73-75]. Nevertheless, time allocation to social activities varied among elderly men and women across countries. In general, men allocated more time to social activities than women in all countries, except for Spain (Additional file 1: Table S1). Previous studies have also stressed the importance of older adult's participation in social support and network activities such as religious activities [74], social or other clubs [76] for psychological well-being [77] and increase in survival among older people [78]. For example, a study by Engelhardt et al. [79] found that social involvement enhances cognitive functioning among the elderly. Also, social participation has been found to be related to low level of stress and depression among the elderly [77, 80]. We therefore expected social activities to ameliorate stress among older adults, however, we found no significant direct relationship between social support activities and stress among elderly men and women. One possible reason for the lack of association may be related to measurement issues. Social activities was measured by the amount of time spent on activities such as religious activities, visiting friends, excursions and observer sports (Additional file 1: Table S2), and not measuring the quality of social support and network size [81]. These aspects of social network have been found as protective factors against stress in prior research [82].

Work-related time use activities (i.e. housework and paid work) were directly associated with both self-reported health and stress. Paid work was negatively associated with stress among men, but this association 
was not found among women. Although the amount of time allocated to paid work activities among the elderly was very small compared to young adults [11], we found paid work at older ages to be directly linked with reduced stress among men. This is consistent with previous findings that support the reduced role-strain hypothesis [83], that suggests that older adults may engage in less demanding and part-time jobs after retirement, which might be less stressful for them, especially for retired men [83]. Even though we were unable to account separately for older adults' engagement in part-time work in our sample, we found that only about $5 \%$ and $2 \%$ of elderly men and women respectively in Western Europe were in paid employment (Table 1). Recent figures also shows that less than $5 \%$ of elderly people in Europe aged 65 years and above were still employed. Nevertheless, the employment rate for the subgroup 65-69 years has increased from $8.8 \%$ in 2005 to $10.5 \%$ in 2011 [84]. In the US, a higher participation rate in paid employment after retirement than in Europe has been noted [11, 84]. The explanation is that most Western European countries have universal social and healthcare systems [84]. In contrast, the high cost of health care in the US may account for the high employment rate among the older population [85]. Currently, it is still unclear whether working at old age is beneficial to older adult's physical health $[11,38,86]$. Nonetheless, this current study found paid work at old age to be positively related with self-reported health for both genders, as found in some previous studies $[11,86]$, but the magnitude of the effect varied among men and women [86]. Perhaps, the social network that older adults gain or maintain at their workplace [86] combined with low levels of depressions at old age, due to the reduction in the amount of time devoted to paid work activities [83] may explain these favorable direct correlations between paid work and self-reported health among the elderly.

Regarding time devoted to housework, the result showed gender and cross-national variations (Additional file 1: Table S1). Furthermore, consistent with previous evidence [11, 26, 29, 31, 32, 39], we found that women devote more to housework activities than men. In spite of these gender differences, time devoted to housework was directly and positively related with self-reported health among both genders, consistent with prior evidence $[11,39]$, although the investigations of the association between time devoted to housework and health in prior research were inconsistent $[11,39,87,88]$. For example, Lawlor et al. [88] found no association between heavy housework activities and reduced levels of being overweight among older British women. Similarly, a study conducted in China by Wen et al. [87] found negative associations between health status and various types of housework activities among women. On the other hand, Adjei and Brand [39] suggested that some hours devoted to housework activities might improve the health of the elderly. This inconsistency may be due to the different contexts and health outcomes $[11,87]$.

While we did not find any direct negative impact of housework on self-reported health in this current study, we did find this when examining stress in terms of time pressure among both genders. When potential indirect pathways were examined, mediation analysis did not show an indirect effect of housework on self-reported health via stress. Among the working population, prior studies showed that working-age adults who devote more time to housework activities experience high levels of stress and increased depression [36, 37]. It has been suggested that multiple role demands and work overload may be possible explanations for this psychological health outcome [41, 89]. However, since it was suggested in previous studies $[11,39]$ that the positive relationship between work-related time use activities and physical health is attributable to less stress at old age, we therefore expected to find support for the time availability theory suggesting that older adults after retirement may not have the same time pressure as younger adults. Indeed, in line with these expectations, we found that stress in terms of time pressure does not mediate or indirectly influence the positive associations between housework, paid work and self-reported health among elderly men and women.

Our analysis is not without limitations. First, the cross-sectional design of the research prevents conclusions about causality, and it is not possible to determine directionality in the relationship between the investigated factors and self-reported health. Second, although we have controlled for a variety of confounders, biological and behavioral determinants of health status among older adults $[12,15]$ were not included in the theoretical model, due to data constraints. Third, this study used subjective rather than objective reports of time use activities and health status. However, estimates from dedicated time use surveys are more reliable and accurate than survey estimates [90, 91]. Furthermore, self-reported health has consistently been shown to be a valid measure of current health status [92]. Nonetheless, we acknowledge that there may be gender differences in health reporting behavior [93]. Fourth, due to data limitations, this study relied on time use surveys that have been collected at different points in time with variations in the modes of data collection in the chosen countries, however, evaluation studies suggest that these differences do not affect the comparability of the data [94]. Notwithstanding these limitations, the study provided the first overview of the inter-related pathways through which psychosocial factors impact the health of older adults using a large-scale and homogeneous time use data set from Europe. 


\section{Conclusions}

The results from the SEM models provided evidence of the interrelating paths between psychosocial factors and health status among elderly men and women in western European countries. Our findings suggest that although stress in terms of time pressure has a strong direct negative effect on health, it does not indirectly influence the positive effects of work-related time use activities on self-reported health among elderly men and women. The results support the time availability hypothesis that older adults may not have the same time pressure as younger adults after retirement.

\section{Additional file}

Additional file 1: Table S1. General description of time use activities (means and SD), men and women, by country. Table S2. Typology of activities. Table S3. General description of the study sample (in percentages) by country, men. Table S4. General description of the study sample (in percentages) by country, women. (DOCX $35 \mathrm{~kb}$ )

\section{Abbreviations}

CFI: Comparative Fit Index; MTUS: Multinational Time Use Study; RMSEA: Root Mean Square Error of Approximation; SEM: Structural Equation Modelling; SES: Socioeconomic Status

\section{Acknowledgments}

The authors thank Prof. Dr. med. Hajo Zeeb, Associate Prof. Elisabeth Jonas, Dr. Ingeborg Jahn and Dr. Iris Shiripinda for their useful comments and suggestions.

\section{Availability of data and materials}

The data used for this study comes from the Multinational Time Use Study (MTUS). Detailed information on the survey design and characteristics are provided on the MTUS homepage, https://www.timeuse.org/mtus.

\section{Authors' contributions}

NKA conceived the study, performed statistical analysis and drafted the manuscript. NKA, TB and KRJ critically revised and reviewed the manuscript. All authors read and approved the final manuscript.

\section{Ethics approval and consent to participate}

The authors were granted approval from the Multinational Time Use Study Review Board to obtain and use the collected data for analysis. All data were anonymized prior to the authors receiving the data.

\section{Consent for publication}

Not applicable.

\section{Competing interests}

The authors declare that they have no competing interests.

\section{Publisher's Note}

Springer Nature remains neutral with regard to jurisdictional claims in published maps and institutional affiliations.

\section{Author details}

${ }^{1}$ Department of Prevention and Evaluation, Leibniz Institute for Prevention Research and Epidemiology - BIPS, Unit Social Epidemiology, Achterstrasse 30, D-28359 Bremen, Germany. ${ }^{2}$ Health Sciences Bremen, University of Bremen, Bremen, Germany. ${ }^{3}$ Department of Sociology, University Essex, Colchester, UK. ${ }^{4}$ Department of Health Sciences, Africa University, Mutare, Zimbabwe.
Received: 3 April 2018 Accepted: 9 August 2018

Published online: 16 August 2018

\section{References}

1. Barreto SM, Giatti L, Kalache A. Gender inequalities in health among older Brazilian adults. Rev Panam Salud Publica. 2004;16(2):110-7. https:/doi.org/ 10.1590/S1020-49892004000800006.

2. Denton M, Prus S, Walters V. Gender differences in health: a Canadian study of the psychosocial, structural and behavioural determinants of health. Soc Sci Med. 2004;58(12):2585-600

3. Rueda S, Artazcoz L. Gender inequality in health among elderly people in a combined framework of socioeconomic position, family characteristics and social support. Ageing Soc. 2009;29(04):625-47.

4. Arber S, Ginn J. Gender and inequalities in health in later life. Soc Sci Med. 1993;36(1):33-46.

5. McDonough P, Walters V. Gender and health: reassessing patterns and explanations. Soc Sci Med. 2001;52(4):547-59.

6. Gorman BK, Read JG. Gender disparities in adult health: an examination of three measures of morbidity. J Health Soc Behav. 2006;47(2):95-110.

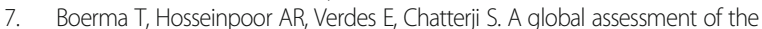
gender gap in self-reported health with survey data from 59 countries. BMC Public Health. 2016;16(1):675

8. Hosseinpoor AR, Williams JS, Amin A, de Carvalho IA, Beard J, Boerma T, et al. Social Determinants of Self-Reported Health in Women and Men: Understanding the Role of Gender in Population Health. PLoS ONE. 2012;7(4): e34799. https://doi.org/10.1371/journal.pone.0034799.

9. Macintyre S, Hunt K, Sweeting H. Gender differences in health: are things really as simple as they seem? Soc Sci Med. 1996;42(4):617-24.

10. Leinonen R, Heikkinen E, Jylhä M. Self-rated health and self-assessed change in health in elderly men and women-a five-year longitudinal study. Soc Sci Med. 1998:46(4):591-7.

11. Adjei NK, Brand T, Zeeb H. Gender inequality in self-reported health among the elderly in contemporary welfare countries: a cross-country analysis of time use activities, socioeconomic positions and family characteristics. PLoS One. 2017;12(9):e0184676.

12. Rieker PP, Bird CE. Rethinking gender differences in health: why we need to integrate social and biological perspectives. J Gerontol B Psychol Sci Soc Sci. 2005;60(Special Issue 2):S40-S7.

13. Short SE, Yang YC, Jenkins TM. Sex, gender, genetics, and health. Am J Public Health. 2013;103(S1):S93-S101.

14. Oksuzyan A, Shkolnikova M, Vaupel JW, Christensen K, Shkolnikov VM. Sex differences in biological markers of health in the study of stress, aging and health in Russia. PLoS One. 2015;10(6):e0131691.

15. Kiecolt-Glaser JK, McGuire L, Robles TF, Glaser R. Emotions, morbidity, and mortality: new perspectives from psychoneuroimmunology. Annu Rev Psychol. 2002:53(1):83-107.

16. Prus SG, Gee E. Gender differences in the influence of economic, lifestyle, and psychosocial factors on later-life health. Can J Public Health. 2003:94:306-9.

17. Dalstra JAA, Kunst AE, Mackenbach JP. A comparative appraisal of the relationship of education, income and housing tenure with less than good health among the elderly in Europe. Soc Sci Med. 2006;62(8):2046-60. https://doi.org/10.1016/j.socscimed.2005.09.001.

18. McLeod JD, Kessler RC. Socioeconomic status differences in vulnerability to undesirable life events. J Health Soc Behav. 1990;31:162-72.

19. House JS, Lepkowski JM, Kinney AM, Mero RP, Kessler RC, Herzog AR. The social stratification of aging and health. J Health Soc Behav. 1994;35(3):21334. https://doi.org/10.2307/2137277.

20. Gauthier AH, Smeeding TM. Time use at older ages cross-National Differences. Res Aging. 2003:25(3):247-74. https://doi.org/10.1177/0164027503025003003.

21. Krantz-Kent R, Stewart J. How do older Americans spend their time. Mon Labor Rev. 2007:130:8.

22. Zimmer Z, Lin H-S. Leisure activity and well-being among the elderly in Taiwan: testing hypotheses in an Asian setting. J Cross Cult Gerontol. 1996;11(2):167-86.

23. Cornwell B, Laumann EO, Schumm LP. The social connectedness of older adults: a National Profile*. Am Sociol Rev. 2008;73(2):185-203.

24. Einolf $\mathrm{CJ}$. Will the boomers volunteer during retirement? Comparing the baby boom, silent, and long civic cohorts. Nonprofit Volunt Sect Q. 2009; 38(2):181-99. https://doi.org/10.1177/0899764008315182.

25. Musick MA, Herzog AR, House JS. Volunteering and mortality among older adults: findings from a national sample. J Gerontol Ser B Psychol Sci Soc Sci. 1999;54(3):S173-S80. 
26. Bird CE, Fremont AM. Gender, time use, and health. J Health Soc Behav. 1991;32(2):114-29. https://doi.org/10.2307/2137147.

27. Bartley M, Sacker A, Firth D, Fitzpatrick R. Social position, social roles and women's health in England: changing relationships 1984-1993. Soc Sci Med. 1999;48(1):99-115.

28. Verbrugge LM, Madans $\mathrm{JH}$. Social roles and health trends of American women. Milbank Mem Fund Q Health Soc. 1985;63:691-735.

29. Anxo D, Flood L, Mencarini L, Pailhé A, Solaz A, Tanturri ML. Time allocation between work and family over the life-cycle: a comparative gender analysis of Italy, France, Sweden and the United States. Bonn: Institute for the Study of Labor; 2007. (IZA Discussion Paper No. 3193).

30. Szinovacz ME. Changes in housework after retirement: a panel analysis. J Marriage Fam. 2000;62(1):78-92.

31. Bianchi SM, Sayer LC, Milkie MA, Robinson JP. Housework: who did, does or will do it, and how much does it matter? Soc Forces. 2012;91(1):55-63.

32. Sayer LC. Trends in Women's and Men's Time Use, 1965-2012: Back to the future? Gender and Couple Relationships. Cham: Springer; 2016. p. 43-77.

33. Coltrane S. Research on household labor: modeling and measuring the social embeddedness of routine family work. J Marriage Fam. 2000;62(4):1208-33.

34. Barnett RC, Shen Y-C. Gender, high-and low-schedule-control housework tasks, and psychological distress a study of dual-earner couples. J Fam Issues. 1997;18(4):403-28.

35. Reid MG. Economics of household production. New York: Wiley; 1934.

36. Bird CE. Gender, household labor, and psychological distress: the impact of the amount and division of housework. J Health Soc Behav. 1999:40:32-45.

37. Glass J, Fujimoto T. Housework, paid work, and depression among husbands and wives. J Health Soc Behav. 1994;35:179-91.

38. Luoh M-C, Herzog AR. Individual consequences of volunteer and paid work in old age: health and mortality. J Health Soc Behav. 2002;43:490-509.

39. Adjei NK, Brand T. Investigating the associations between productive housework activities, sleep hours and self-reported health among elderly men and women in western industrialised countries. BMC Public Health. 2018;18(1):110

40. Bratberg E, Dahl SÅ, Risa AE. 'The double burden': do combinations of career and family obligations increase sickness absence among women? Eur Sociol Rev. 2002;18(2):233-49.

41. Lundberg U. On the psychobiology of stress and health, Time pressure and stress in human judgment and decision making. Boston: Springer; 1993. p. 41-53.

42. Gautam R, Saito T, Kai I. Leisure and religious activity participation and mental health: gender analysis of older adults in Nepal. BMC Public Health. 2007;7(1):299.

43. Fisher K, Gershuny J, Gauthier A. Multinational time use study-User's guide and documentation. Oxford: Centre for Time Use Research; 2012.

44. Aquino JA, Russell DW, Cutrona CE, Altmaier EM. Employment status, social support, and life satisfaction among the elderly. J Couns Psychol. 1996;43(4):480

45. Hoshino A, Amano S, Suzuki K, Suwa M. Relationships between depression and stress factors in housework and paid work among Japanese women. Hong Kong J Occup Ther. 2016;27:35-41.

46. Gunnarsdottir H, Bjereld Y, Hensing G, Petzold M, Povlsen L. Associations between parents' subjective time pressure and mental health problems among children in the Nordic countries: a population based study. BMC Public Health. 2015;15(1):353.

47. StataCorp. Stata Statistical Software Release 14. College Station: Stata Press Publication; 2015.

48. Rubin DB. Causal inference using potential outcomes: design, modeling, decisions. J Am Stat Assoc. 2005;100(469):322-31.

49. Hooper D, Coughlan J, Mullen MR. Structural equation modeling: Guidelines for determining model fit. Electron J Bus Res Methods. 2008;6(1):53-6.

50. StataCorp. Stata 14 Base Reference Manual. College Station, TX: Stata Press; 2015.

51. Wilkinson RG, Marmot MG. Social determinants of health: the solid facts. Copenhagen: WHO Regional Office for Europe; 2003.

52. Adler NE, Boyce T, Chesney MA, Cohen S, Folkman S, Kahn RL, et al. Socioeconomic status and health. The challenge of the gradient. Am Psychol. 1994;49(1):15-24.

53. Assari S, Lankarani MM. Does multi-morbidity mediate the effect of socioeconomics on self-rated health? Cross-country differences. Int J Prev Med. 2015;6:85.

54. Lankarani MM, Shah S, Assari S. Gender Differences in Vulnerability to Socioeconomic Status on Self-Rated Health in 15 Countries. Womens Health Bull. 2017;4(3):e45280.
55. Parker M, Ahacic K, Thorslund M, Lundberg O. Socioeconomic status and health among elderly people in Sweden. Ann N Y Acad Sci. 1999; 896(1):383-5.

56. Lima-Costa MF, Barreto SM, Firmo JO, Uchoa E. Socioeconomic position and health in a population of Brazilian elderly: the Bambui health and aging study (BHAS). Rev Panam Salud Publica. 2003;13(6):387-94.

57. Talala KM, Martelin TP, Haukkala AH, Härkänen TT, Prättälä RS. Socioeconomic differences in self-reported insomnia and stress in Finland from 1979 to 2002: a population-based repeated cross-sectional survey. BMC Public Health. 2012;12(1):650.

58. Umberson D, Liu H, Powers D. Marital status, marital transitions, and body weight*. J Health Soc Behav. 2009;50(3):327-43.

59. Pienta AM, Hayward MD, Jenkins KR. Health consequences of marriage for the retirement years. J Fam Issues. 2000;21(5):559-86.

60. Wright MR, Brown SL. Psychological well-being among older adults: the role of partnership status. J Marriage Fam. 2017;79(3):833-49.

61. Kiecolt-Glaser JK, Newton TL. Marriage and health: his and hers. Psychol Bull. 2001;127(4):472.

62. Jang S-N, Kawachi I, Chang J, Boo K, Shin H-G, Lee H, et al. Marital status, gender, and depression: analysis of the baseline survey of the Korean longitudinal study of ageing (KLoSA). Soc Sci Med. 2009:69(11):1608-15.

63. St John PD, Montgomery PR. Marital status, partner satisfaction, and depressive symptoms in older men and women. Can J Psychiatry. 2009; 54(7):487-92.

64. Yim HJ, Park HA, Kang JH, Kim K-W, Cho YG, Hur Yl, et al. Marital status and health behavior in middle-aged Korean adults. Korean J Fam Med. 2012;33(6):390-7.

65. Gove WR. Sex differences in mental illness among adult women and men: An evaluation of four questions raised regarding the evidence of higher rates in women. Soc Sci Med. 1978;12(3B):187-98. https://doi.org/10.1016/ 0160-7987(78)90032-7.

66. Umberson D. Gender, marital status and the social control of health behavior. Soc Sci Med. 1992;34(8):907-17.

67. Randall AK, Bodenmann G. The role of stress on close relationships and marital satisfaction. Clin Psychol Rev. 2009:29(2):105-15.

68. Mattingly MJ, Sayer LC. Under pressure: gender differences in the relationship between free time and feeling rushed. J Marriage Fam. 2006; 68(1):205-21.

69. Neff LA, Karney BR. Stress crossover in newlywed marriage: a longitudinal and dyadic perspective. J Marriage Fam. 2007;69(3):594-607.

70. Singh L, Arokiasamy P, Singh PK, Rai RK. Determinants of gender differences in self-rated health among older population: evidence from India. SAGE Open. 2013;3(2):2158244013487914.

71. Mroczek DK, Almeida DM. The effect of daily stress, personality, and age on daily negative affect. J Pers. 2004;72(2):355-78.

72. Stawski RS, Sliwinski MJ, Almeida DM, Smyth JM. Reported exposure and emotional reactivity to daily stressors: the roles of adult age and global perceived stress. Psychol Aging. 2008;23(1):52.

73. Al-Kandari Y. Social support and its relationship to hypertension and general health status among older adults in the mobile care unit in Kuwait. J Cross Cult Gerontol. 2011;26(2):175-87.

74. Al-Kandari YY. Religiosity, social support, and health among the elderly in Kuwait. J Muslim Ment Health. 2011;6(1):81-98.

75. Caetano SC, Silva CM, Vettore MV. Gender differences in the association of perceived social support and social network with self-rated health status among older adults: a population-based study in Brazil. BMC Geriatr. 2013;13(1):122.

76. Tomioka K, Kurumatani N, Hosoi H. Positive and negative influences of social participation on physical and mental health among communitydwelling elderly aged 65-70 years: a cross-sectional study in Japan. BMC Geriatr. 2017;17(1):111.

77. Chiao C, Weng L-J, Botticello AL. Social participation reduces depressive symptoms among older adults: an 18-year longitudinal analysis in Taiwan. BMC Public Health. 2011;11(1):292.

78. Glass TA, De Leon CM, Marottoli RA, Berkman LF. Population based study of social and productive activities as predictors of survival among elderly Americans. BMJ. 1999;319(7208):478-83

79. Engelhardt H, Buber I, Skirbekk V, Prskawetz A. Social involvement, behavioural risks and cognitive functioning among older people. Ageing Soc. 2010;30(5):779-809.

80. Burke KE, Schnittger R, O'Dea B, Buckley V, Wherton JP, Lawlor BA. Factors associated with perceived health in older adult Irish population. Aging Ment Health. 2012;16(3):288-95. 
81. Fiori KL, Smith J, Antonucci TC. Social network types among older adults: a multidimensional approach. J Gerontol Ser B Psychol Sci Soc Sci. 2007;62(6): P322-P30.

82. Cohen S, Wills TA. Stress, social support, and the buffering hypothesis. Psychol Bull. 1985;98(2):310.

83. Kim JE, Moen P. Retirement transitions, gender, and psychological wellbeing: a life-course, ecological model. J Gerontol Ser B Psychol Sci Soc Sci. 2002;57(3):P212-P22

84. Eurofound. Income from work after retirement in the EU. Luxembourg: Publications Office of the European Union; 2012.

85. Friedberg L. The recent trend towards later retirement. Women. 2007;55:64.

86. Li Y, Xu L, Chi I, Guo P. Participation in productive activities and health outcomes among older adults in urban China. The Gerontologist. 2013; 54(5):784-96.

87. Wen $X$, Liang Y, Zhu J, Wu T. The effects of housework on the health of retired older adults: a preliminary investigation from the Tongji-Dongfeng cohort study, China. PloS one. 2013;8(3):e57232.

88. Lawlor D, Taylor M, Bedford C, Ebrahim S. Is housework good for health? Levels of physical activity and factors associated with activity in elderly women. Results from the British Women's heart and health study. J Epidemiol Community Health. 2002;56(6):473-8.

89. Lundberg U. Influence of paid and unpaid work on psychophysiological stress responses of men and women. J Occup Health Psychol. 1996;1 (2):117.

90. Bonke J. Paid work and unpaid work: diary information versus questionnaire information. Soc Indic Res. 2005;70(3):349-68. https://doi.org/10.1007/ s11205-004-1547-6.

91. Kan MY, Pudney S. Measurement error in stylized and diary data on time use. Sociol Methodol. 2008:38(1):101-32.

92. Idler EL, Benyamini Y. Self-rated health and mortality: a review of twentyseven community studies. J Health Soc Behav. 1997;38(1):21-37.

93. Assari S. Gender differences in the predictive role of self-rated health on short-term risk of mortality among older adults. SAGE Open Med. 2016;4 2050312116666975.

94. Robinson J, Godbey G. Time for life: the surprising ways Americans use their time. Pennsylvania: Penn State University Press; 2010.

Ready to submit your research? Choose BMC and benefit from:

- fast, convenient online submission

- thorough peer review by experienced researchers in your field

- rapid publication on acceptance

- support for research data, including large and complex data types

- gold Open Access which fosters wider collaboration and increased citations

- maximum visibility for your research: over $100 \mathrm{M}$ website views per year

At $\mathrm{BMC}$, research is always in progress.

Learn more biomedcentral.com/submissions 